\title{
Exames de imagem como método complementar para o diagnóstico da COVID-19: revisão integrativa de literatura
}

\section{Imaging exams as a complementary method for the diagnosis of COVID-19: integrative literature review}

\author{
Laiana de Souza Silva ${ }^{1}$. Kelly Cristina Lira de Andrade ${ }^{2}$. Maria Lúcia Lima Soares ${ }^{3}$. \\ 1 Centro Universitário CESMAC, Maceió, Alagoas, Brasil.
}

\section{RESUMO}

Objetivo: Analisar alterações observadas nos exames de imagem como método de investigação complementar no processo de diagnóstico da COVID-19. Materiais e métodos: Revisão integrativa da literatura realizada por meio do levantamento bibliográfico nas bases de dados MEDLINE, Scielo e periódicos nacionais e internacionais relacionados a área de interesse através dos descritores: "Coronavirus infections", "diagnosis", "diagnostic imaging" and "radiology". Resultados: Foram identificadas publicações nas duas bases de dados científicas e nos três periódicos analisados, onde foram selecionados os artigos que possuíam relação com a área temática voltada à saúde e as condições de diagnóstico do novo coronavírus. A amostra foi composta por 8 artigos. A radiografia de tórax pode detectar várias áreas irregulares de opacidades em vidro fosco ou consolidações. Desse modo, foi observado o papel central dos exames de imagem na detecção e gerenciamento precoces das manifestações pulmonares do COVID-19, além dos achados sugestivos da doença. Conclusão: Os achados tomográficos não são preditores da evolução clínica nem unicamente responsáveis pelo diagnóstico dessa doença, mas quando associados aos exames de RT-PCR permitem diagnóstico e tratamento precoces, prevenindo o retardo do isolamento do paciente.

Palavras-chave: Infecções por coronavírus. Diagnóstico. Diagnóstico por imagem. Radiologia.

\section{ABSTRACT}

Objective: To analyze changes observed in imaging exams as a complementary investigation method in the COVID-19 diagnostic process. Materials and methods: Integrative literature review carried out through bibliographic survey in the MEDLINE, Scielo and national and international journals related to the area of interest through the descriptors: "Coronavirus Infections", "diagnosis", "diagnostic imaging" and "radiology". Results: Publications were identified in the two scientific databases and in the three analyzed journals, where articles that were related to the thematic area related to health and the diagnostic conditions of the new coronavirus were selected. The sample consisted of 8 articles. Chest radiography can detect several irregular areas of groundglass opacities or consolidations. Thus, the central role of imaging studies in the early detection and management of COVID-19 pulmonary manifestations was observed, in addition to findings suggestive of the disease. Conclusion: Tomographic findings are not predictors of clinical evolution or solely responsible for the diagnosis of this disease, but when associated with RT-PCR exams, they allow early diagnosis and treatment, preventing delayed patient isolation.

Keywords: Coronavirus Infections. Diagnosis. Diagnostic imaging. Radiology.

Autor correspondente: Laiana de Souza Silva, Rua Íris Alagoense, 281, Farol, Maceió, Alagoas, Brasil. CEP: 57051-370. Telefone: +55 87 $99635-$ 1881. E-mail: laiana_souza19@hotmail.com

Conflito de interesses: Não há qualquer conflito de interesses por parte de qualquer um dos autores.

Recebido em: 07 Set 2020; Revisado em: 05 Jan 2021; Aceito em: 02 Mar 2021. 


\section{INTRODUÇÃO}

O surto de infecção pelo novo coronavírus que ocorreu na cidade de Wuhan, na China, em dezembro de 2019, resultou na disseminação deste vírus altamente contagioso levando a um número crescente de infecções e mortes, que já superaram o surto de SARS-CoV que ocorreu na China entre 2002 e 2003. Atualmente é declarado como uma pandemia, anunciada pela Organização Mundial da Saúde (OMS) no mês de março de 2020 .

O vírus causador da doença conhecida por COVID-19, recebe o nome de SARS-CoV-2 (severe acute respiratory syndrome coronavírus 2) devido a uma das suas principais complicações ser a Síndrome Aguda Respiratória Grave. Os coronavírus desencadeiam sintomatologia frequentemente associada a problemas respiratórios, como tosse seca e dispneia, além de febre, fadiga e calafrios. O diagnóstico etiológico pode se dar a partir da detecção do RNA do SARS-CoV-2 por reverse-transcriptase polymerase chain reaction (RT-PCR, reação em cadeia da polimerase com transcrição reversa) em material colhido da nasofaringe ou da orofaringe. ${ }^{1}$

Resultados falso-negativos de RT-PCR (detecção do RNA viral) representam um desafio clínico, uma vez que o diagnóstico incorreto de um único paciente pode resultar em grandes surtos através de contatos futuros - e por isso, na China, os exames de imagem foram muito utilizados para identificação dessa nova doença. ${ }^{2}$ Nesse contexto, embora o uso da tomografia computadorizada (TC) de tórax como ferramenta de triagem não esteja ainda estabelecido, estudos recentes têm demonstrado um papel central da TC na detecção e gerenciamento precoces das manifestações pulmonares do COVID-19, com alta sensibilidade, mas com especificidade ainda limitada, ${ }^{3}$ o que faz com que a TC não tenha valor preditivo negativo confiável para retirar pacientes do isolamento.

Ainda em relação aos testes diagnósticos, pode-se considerar que o RT-PCR, além de muitas vezes não se encontrar disponível devido à falta de kits e reagentes, também possui tempo de resposta variável, levando de horas a dias para ser concluído, enquanto que uma radiografia de tórax e uma tomografia computadorizada (TC) do tórax são mais disponíveis e rápidas, ${ }^{4}$ apesar de pouco específicas. Realização de exames de imagem em pacientes com o RT-PCR positivo aumenta a sensibilidade (97\%), porém, persiste baixa especificidade (25\%), pois os achados de imagem podem simular infecção pulmonar de outras etiologias. ${ }^{1}$

Desta forma, o objetivo do presente estudo é apresentar os achados clínicos sugestivos nos exames de imagem, principalmente na TC, e sua importância como investigação complementar no processo de diagnóstico da COVID-19.

\section{METODOLOGIA}

Para a realização do estudo foi utilizado o método de revisão integrativa da literatura, o qual consistiu em uma busca mais ampla com o instrumento da Prática Baseada em Evidência (PBE). Para o desenvolvimento do estudo, foi formulado o seguinte questionamento: "Quais os achados clínicos que evidenciam o uso da Imagem como exame complementar ao diagnóstico do COVID-19?".

Para responder à pergunta norteadora foram realizadas buscas nas bases de dados científicas eletrônicas Scielo e MEDLINE e periódicos nacionais e internacionais relacionados a área de interesse (Revista Brasileira de Pneumonia, American Journal of Roentgenology e Radiologia: Imagem Cardiotorácica). A seleção do descritor utilizado no processo de busca foi mediante consulta aos descritores em ciências da saúde (DECS) - da Biblioteca Virtual em Saúde (BVS) e Medical Subject Headings (meSH). Foram utilizados os seguintes descritores para as palavras-chave e suas combinações: "Coronavirus infections", "diagnosis", "diagnostic imaging" and "radiology", além do operador boleano "AND".

Como critérios de elegibilidade foram selecionados os artigos que tiveram publicação em fevereiro, março e abril de 2020, sem distinção de idioma, sendo encontrados em inglês e português, além de estarem intimamente relacionados à área temática voltada à saúde e às condições de diagnóstico do novo coronavírus. Assim sendo, foram descartados os que não apresentavam relação direta com o tema proposto, como exemplo, artigos específicos sobre prevenção da contaminação pelo novo coronavírus nos setores de radiologia. Após a leitura dos títulos, resumos e artigos completos, os artigos selecionados foram analisados de maneira qualitativa.

\section{RESULTADOS}

Foram identificadas publicações nas duas bases de dados diferentes e nos três periódicos analisados, na PubMed foi realizada a combinação de todos os descritores e 207 artigos foram encontrados através dos filtros "fevereiro - abril 2020" e "somente humanos", e a partir da leitura de todos os títulos e de 19 resumos selecionados para leitura de acordo com o objetivo do trabalho, foram selecionados apenas três. Na base de dados Scielo, foi utilizado como descritor apenas "coronavírus infections", selecionados os filtros "ano de publicação: 2020" e "periódico Jornal Brasileiro de Pneumologia (JBP)", onde foi encontrado apenas um artigo, este foi selecionado.

No American Journal of Roentgenology foram encontrados dois artigos. Na Revista Radiologia: Imagem Cardiotorácica foi encontrado um artigo e na Revista Chinesa de Radiologia um artigo. Desse modo, os oito artigos selecionados foram analisados de maneira qualitativa.

A Figura 1 apresenta o resultado quantitativo das buscas e o Quadro 1 os dados qualitativos dos artigos incluídos. 
Figura 1. Fluxograma da quantidade de artigos encontrados e selecionados nas bases de dados e periódicos.

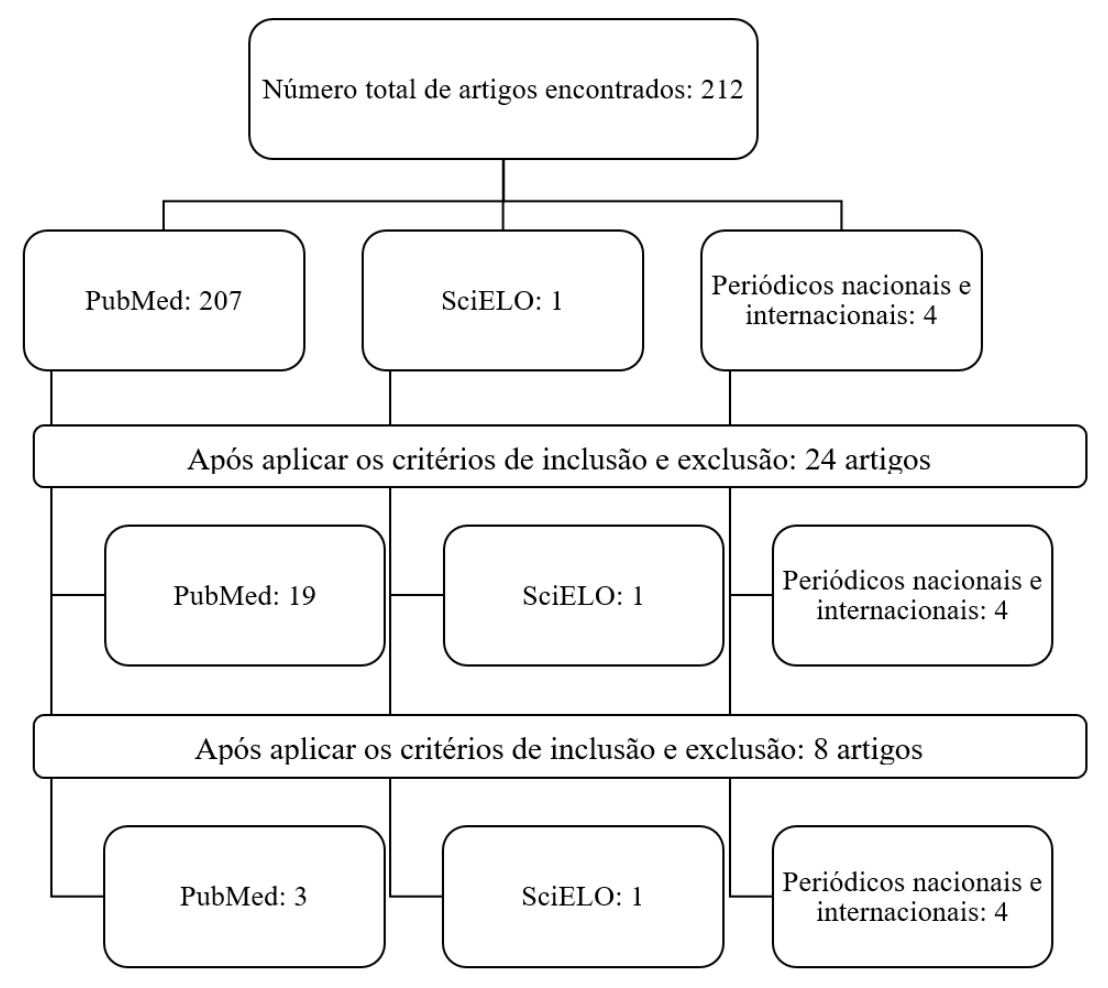

Quadro 1. Análise qualitativa dos artigos incluídos.

\begin{tabular}{|c|c|c|c|c|c|}
\hline Nome do Artigo & Autor & Mês/ano/local & Objetivo & Resultados & Conclusão \\
\hline $\begin{array}{l}\text { Pneumonia por } \\
\text { COVID-19: qual o } \\
\text { papel da imagem } \\
\text { no diagnóstico? }\end{array}$ & $\begin{array}{l}\text { Araujo-filho } \\
\text { et al }\end{array}$ & $\begin{array}{l}\text { Março/2020/ } \\
\text { Brasil }\end{array}$ & $\begin{array}{l}\text { Analisar e demonstrar } \\
\text { os achados pulmonares } \\
\text { típicos da infecção } \\
\text { por COVID-19, desde } \\
\text { que seja confirmada } \\
\text { laboratorialmente por } \\
\text { RT-PCR. }\end{array}$ & $\begin{array}{l}\text { Estima-se que até } 50 \% \text { dos pacientes } \\
\text { infectados por COVID-19 possam } \\
\text { apresentar TC de tórax normal } \\
\text { nos dois primeiros dias após o } \\
\text { aparecimento dos sintomas. Além } \\
\text { disso, pacientes com infecção por } \\
\text { COVID-19 confirmada por RT- } \\
\text { PCR positivo e TC de tórax normal } \\
\text { na admissão após 2-3 semanas } \\
\text { constituem evidência suficiente de } \\
\text { que uma TC de tórax normal não } \\
\text { exclui o diagnóstico, sobretudo em } \\
\text { pacientes com infecção recente. }\end{array}$ & $\begin{array}{l}\text { A TC não deve ser } \\
\text { usada na triagem de } \\
\text { COVID-19 em pacientes } \\
\text { assintomáticos, devendo } \\
\text { ser considerada em } \\
\text { pacientes hospitalizados, } \\
\text { sintomáticos ou em } \\
\text { situações clínicas } \\
\text { específicas. }\end{array}$ \\
\hline $\begin{array}{l}\text { Apresentação } \\
\text { tomográfica da } \\
\text { infecção pulmonar } \\
\text { na COVID-19: } \\
\text { experiência } \\
\text { brasileira inicial. }\end{array}$ & Chate et al & $\begin{array}{l}\text { Março/2020/ } \\
\text { Brasil }\end{array}$ & $\begin{array}{l}\text { Descrever os achados } \\
\text { tomográficos em uma } \\
\text { série inicial de } 12 \\
\text { pacientes }\end{array}$ & $\begin{array}{l}\text { Foi encontrado opacidades em vidro } \\
\text { fosco, em } 12 \text { pacientes (100\%); } \\
\text { pavimentação em mosaico, em } 7 \\
(58 \%) \text {; consolidação alveolar, em } \\
4(33 \%) \text {; sinal do halo invertido, } \\
\text { em } 1(8 \%) \text { e derrame pleural, } \\
\text { em } 1(8 \%) \text {. Nódulos, cavidades } \\
\text { e linfonodomegalias não foram } \\
\text { identificados em nossa amostra. }\end{array}$ & $\begin{array}{l}\text { É fundamental que } \\
\text { clínicos e radiologistas } \\
\text { estejam familiarizados } \\
\text { com as formas mais } \\
\text { comuns de apresentação } \\
\text { por imagem da } \\
\text { COVID-19, assim como } \\
\text { com a evolução esperada } \\
\text { dos achados, de modo } \\
\text { que possam contribuir } \\
\text { para a identificação } \\
\text { mais precoce dos casos } \\
\text { e, consequentemente, } \\
\text { redução } \\
\text { consequências e da taxa } \\
\text { de mortalidade da doença. }\end{array}$ \\
\hline
\end{tabular}

Continua. 
Continuação.

Quadro 1. Análise qualitativa dos artigos incluídos.

\begin{tabular}{|c|c|c|c|c|c|}
\hline Nome do Artigo & Autor & Mês/ano/local & Objetivo & Resultados & Conclusão \\
\hline $\begin{array}{l}\text { Radiografia de } \\
\text { tórax e achados } \\
\text { da tomografia } \\
\text { computadorizada } \\
\text { de um paciente } \\
\text { brasileiro com } \\
\text { pneumonia por } \\
\text { COVID-19 }\end{array}$ & $\begin{array}{l}\text { Bruno Lima } \\
\text { Moreira et } \\
\text { al. }\end{array}$ & $\begin{array}{l}\text { Abril/2020/ } \\
\text { Brasil }\end{array}$ & $\begin{array}{l}\text { Correlacionar os } \\
\text { principais sintomas } \\
\text { do COVID-19 com os } \\
\text { achados da tomografia } \\
\text { computadorizada }\end{array}$ & $\begin{array}{l}\text { Paciente foi internado com histórico } \\
\text { de } 4 \text { dias de febre, calafrios, tosse } \\
\text { seca e fadiga, temperatura de } 37,7^{\circ} \mathrm{C} \text {, } \\
\text { FC } 85 \text { bpm, FR } 15 \text { irpm e saturação } \\
\text { de oxigênio de } 94 \% \text {. Nos exames } \\
\text { de imagem, radiografia de tórax } \\
\text { mostrou opacidades pulmonares mal } \\
\text { definidas, a TC revelou opacidades } \\
\text { em vidro fosco periféricas, } \\
\text { envolvendo todos os lobos } \\
\text { pulmonares, onde foram observados } \\
\text { pequenos focos de consolidação. O } \\
\text { teste de RT-PCR em tempo real de } \\
\text { um swab nasofaríngeo confirmou a } \\
\text { infecção por COVID- } 19 \text {. }\end{array}$ & $\begin{array}{l}\text { Os principais } \\
\text { achados tomográficos } \\
\text { da pneumonia } \\
\text { por COVID-19 } \\
\text { incluem opacidades } \\
\text { predominantemente } \\
\text { periféricas em vidro } \\
\text { fosco, padrão de } \\
\text { pavimentação e/ou } \\
\text { consolidação das regiões } \\
\text { pulmonares média e } \\
\text { inferior, geralmente com } \\
\text { envolvimento bilateral e } \\
\text { multilobar. }\end{array}$ \\
\hline $\begin{array}{l}\text { Progresso e } \\
\text { perspectiva no } \\
\text { diagnóstico } \\
\text { por imagem do } \\
\text { COVID-19 }\end{array}$ & Li Fan et al. & $\begin{array}{l}\text { Março/2020/ } \\
\text { China }\end{array}$ & \begin{tabular}{|l|} 
Analisar o progresso \\
e a perspectiva no \\
diagnóstico por imagem \\
a partir de se concentrar \\
na interpretação \\
dos achados da TC, \\
indicando as possíveis \\
bases patológicas, \\
diferenciando o \\
COVID-19 de outras \\
doenças.
\end{tabular} & $\begin{array}{l}\text { Diagnóstico definitivo deve se } \\
\text { basear na história epidemiológica, } \\
\text { nos sintomas clínicos, nas } \\
\text { manifestações laboratoriais e de } \\
\text { imagem, já que não pode ser feito } \\
\text { apenas com base nos recursos de } \\
\text { imagem pois não é suficiente para } \\
\text { diferenciar das outras pneumonias } \\
\text { virais, pneumonias bacterianas, } \\
\text { pneumonias micoplasmáticas e } \\
\text { muitas doenças não infecciosas. }\end{array}$ & $\begin{array}{l}\text { Os achados de imagem } \\
\text { por tomografia } \\
\text { computadorizada não } \\
\text { podem ser usados como } \\
\text { padrão-ouro no diagnóstico } \\
\text { por COVID-19, devido às } \\
\text { características sobrepostas } \\
\text { e inespecíficas de } \\
\text { muitas outras doenças } \\
\text { pulmonares. No entanto, } \\
\text { ainda desempenha } \\
\text { um grande papel na } \\
\text { detecção da existência de } \\
\text { pneumonia, avaliando a } \\
\text { progressão da doença e } \\
\text { monitorando a resposta ao } \\
\text { tratamento. }\end{array}$ \\
\hline $\begin{array}{l}\text { TC de tórax } \\
\text { e doença de } \\
\text { coronavírus } \\
\text { (COVID-19): uma } \\
\text { revisão crítica da } \\
\text { literatura até o } \\
\text { momento. }\end{array}$ & Raptis et al. & $\begin{array}{l}\text { Março/2020/ } \\
\text { Estados } \\
\text { Unidos }\end{array}$ & $\begin{array}{l}\text { Revisar criticamente } \\
\text { alguns dos estudos } \\
\text { mais citados sobre } \\
\text { o uso da tomografia } \\
\text { computadorizada na } \\
\text { detecção do COVID-19 }\end{array}$ & $\begin{array}{l}\text { Nenhuma literatura revisada neste } \\
\text { artigo relata de maneira confiável } \\
\text { uma alta especificidade da TC na } \\
\text { diferenciação da pneumonia por } \\
\text { COVID-19 de outras doenças com } \\
\text { achados tomográficos semelhantes, } \\
\text { no entanto não exclui o valor preditivo } \\
\text { positivo da TC na alta prevalência da } \\
\text { pneumonia por COVID-19. }\end{array}$ & $\begin{array}{l}\text { A TC do tórax } \\
\text { deve ser reservada } \\
\text { para a avaliação } \\
\text { de complicações } \\
\text { da pneumonia por } \\
\text { COVID-19 ou para a } \\
\text { avaliação se houver } \\
\text { suspeita de diagnóstico } \\
\text { alternativo. }\end{array}$ \\
\hline $\begin{array}{l}\text { Achados da } \\
\text { base pulmonar } \\
\text { da doença de } \\
\text { coronavírus } \\
\text { (COVID-19) na } \\
\text { TC abdominal } \\
\text { em pacientes } \\
\text { com sintomas } \\
\text { gastrointestinais } \\
\text { predominantes }\end{array}$ & Siegel et al & $\begin{array}{l}\text { Março/2020/ } \\
\text { Estados } \\
\text { Unidos }\end{array}$ & $\begin{array}{l}\text { Demonstrar a presença } \\
\text { de achados nas bases } \\
\text { pulmonares na TC do } \\
\text { abdome identificado } \\
\text { pelo radiologista em } \\
\text { um paciente que não } \\
\text { apresentou os sintomas } \\
\text { respiratórios típicos da } \\
\text { doença por coronavírus } \\
\text { (COVID-19) }\end{array}$ & $\begin{array}{l}\text { Os achados nas bases pulmonares } \\
\text { foram descritos pelos radiologistas } \\
\text { como opacidades periféricas } \\
\text { e subpleurais em vidro fosco, } \\
\text { geralmente bilaterais, com } \\
\text { configuração nodular, aparência } \\
\text { aparentemente inespecífica, mas } \\
\text { típica do COVID-19. O diagnóstico } \\
\text { diferencial foi sugerido pelo } \\
\text { radiologista abdominal primeiro } \\
\text { e não era originalmente suspeito } \\
\text { no pronto-socorro devido à falta } \\
\text { de sintomas pulmonares típicos } \\
\text { esperados. Os testes subsequentes } \\
\text { de PCR para SARS-COV-2 } \\
\text { confirmaram essas suspeitas. }\end{array}$ & $\begin{array}{l}\text { Os radiologistas abdominais } \\
\text { podem desempenhar } \\
\text { um papel importante } \\
\text { em alertar os médicos } \\
\text { sobre a possibilidade } \\
\text { de infecção por SARS- } \\
\text { CoV-2 em pacientes com } \\
\text { dor abdominal, mas com } \\
\text { suspeita de COVID-19. A } \\
\text { avaliação cuidadosa das } \\
\text { bases pulmonares para as } \\
\text { opacidades típicas de vidro } \\
\text { fosco nodular e distribuído } \\
\text { de forma periférica pode } \\
\text { levar ao diagnóstico correto } \\
\text { antes das manifestações } \\
\text { respiratórias progressivas } \\
\text { da doença. }\end{array}$ \\
\hline
\end{tabular}

Continua. 
Conclusão.

Quadro 1. Análise qualitativa dos artigos incluídos.

\begin{tabular}{|c|c|c|c|c|c|}
\hline Nome do Artigo & Autor & Mês/ano/local & Objetivo & Resultados & Conclusão \\
\hline $\begin{array}{l}\text { O papel da } \\
\text { imagem na nova } \\
\text { pneumonia por } \\
\text { coronavírus } \\
\text { (COVID-19). }\end{array}$ & Yang et al & $\begin{array}{l}\text { Abril/2020/ } \\
\text { China/EUA/ } \\
\text { Reino Unido }\end{array}$ & $\begin{array}{l}\text { Mostrar a importância } \\
\text { que um exame de } \\
\text { imagem de boa } \\
\text { qualidade tem para } \\
\text { identificação precoce e } \\
\text { auxiliar no diagnóstico } \\
\text { do COVID-19 }\end{array}$ & $\begin{array}{l}\text { Os achados típicos de tomografia } \\
\text { computadorizada do COVID-19 } \\
\text { podem não apenas ajudar natriagem } \\
\text { precoce de casos suspeitos, como } \\
\text { exame complementar, mas também } \\
\text { podem monitorar a progressão } \\
\text { clínica e prever complicações } \\
\text { graves, como doenças respiratórias } \\
\text { agudas. Com alta sensibilidade } \\
\text { para COVID-19, a TC de tórax } \\
\text { teria um papel muito importante } \\
\text { no diagnóstico e tratamento de } \\
\text { COVID-19 nas regiões e países de } \\
\text { alto risco. }\end{array}$ & $\begin{array}{l}\text { A imagem do COVID-19, } \\
\text { particularmente na } \\
\text { TC do tórax, tem um } \\
\text { valor muito alto porque } \\
\text { mostra manifestações } \\
\text { características e permite } \\
\text { que os médicos da } \\
\text { linha de frente tenham } \\
\text { diagnóstico primário } \\
\text { em seu primeiro contato } \\
\text { com pacientes suspeitos, } \\
\text { mesmo na presença de } \\
\text { resultados negativos de } \\
\text { laboratório. }\end{array}$ \\
\hline $\begin{array}{l}\text { Declaração de } \\
\text { consenso de } \\
\text { especialistas } \\
\text { da Sociedade } \\
\text { Radiológica da } \\
\text { América do Norte } \\
\text { sobre o relato de } \\
\text { achados de TC no } \\
\text { tórax relacionados } \\
\text { ao COVID-19. }\end{array}$ & $\begin{array}{l}\text { Simpson } \\
\text { et al }\end{array}$ & $\begin{array}{l}\text { Março/2020/ } \\
\text { América do } \\
\text { Norte }\end{array}$ & $\begin{array}{l}\text { Fornecer orientação } \\
\text { aos radiologistas ao } \\
\text { relatar achados de } \\
\text { TC potencialmente } \\
\text { atribuíveis à pneumonia } \\
\text { por COVID-19, } \\
\text { incluindo linguagem } \\
\text { padronizada para } \\
\text { reduzir a variabilidade } \\
\text { dos relatórios ao } \\
\text { abordar a possibilidade } \\
\text { do COVID-19. }\end{array}$ & $\begin{array}{l}\text { O valor preditivo positivo e } \\
\text { negativo da TC do tórax para } \\
\text { COVID-19 é estimado em } 92 \% \\
\text { e } 42 \% \text {, respectivamente, em uma } \\
\text { população com alta probabilidade } \\
\text { de pré-teste para a doença (por } \\
\text { exemplo, prevalência de } 85 \% \\
\text { por RT-PCR). O valor preditivo } \\
\text { negativo relativamente baixo sugere } \\
\text { que a TC pode não ser valiosa como } \\
\text { teste de triagem para COVID-19, } \\
\text { pelo menos nos estágios iniciais } \\
\text { da doença. Além de que os mesmo } \\
\text { achados tomográficos podem estar } \\
\text { relacionados com diagnósticos } \\
\text { diferenciais. }\end{array}$ & $\begin{array}{l}\text { Não é recomendado } \\
\text { o uso de triagem por } \\
\text { TC para pneumonia } \\
\text { por } \\
\text { devido o fato de que as } \\
\text { pneumonias virais têm } \\
\text { uma ampla variedade } \\
\text { de manifestações de } \\
\text { imagem, algumas das } \\
\text { quais são atípicas ou } \\
\text { menos comuns no } \\
\text { COVID-19, como } \\
\text { opacidades em árvore } \\
\text { e outros brônquios, } \\
\text { pequenos nódulos, } \\
\text { espessamento da parede } \\
\text { brônquica e tampões de } \\
\text { muco brônquico. Assim, } \\
\text { o termo "pneumonia } \\
\text { viral" abrange uma série } \\
\text { de achados de imagem, } \\
\text { alguns dos quais não são } \\
\text { típicos do COVID-19. }\end{array}$ \\
\hline
\end{tabular}

\section{DISCUSSÃO}

Estudos recentes têm demonstrado que os exames de imagem, principalmente a TC de tórax, têm demonstrado um papel central na detecção e gerenciamento precoces das manifestações pulmonares do COVID-19, com alta sensibilidade, mas com especificidade ainda limitada, uma vez que os achados tomográficos da pneumonia por COVID-19 são inespecíficos, semelhantes aos de outras infecções pulmonares, e variam de acordo com a fase de acometimento da doença, devendo mandatoriamente ser correlacionados com evidências clínicas e laboratoriais da infecção por COVID-19.

Dessa forma, em pacientes com alta suspeição clínica, achados tomográficos típicos e RT-PCR negativo também têm sido observados, quando então se recomenda que os testes laboratoriais sejam repetidos e o isolamento de contato deva ser considerado. ${ }^{3}$

As alterações de imagem descritas na TC do tórax correspondem a múltiplas áreas irregulares de opacidade em vidro fosco ou consolidações, predominantemente na periferia dos pulmões, sendo extremamente úteis na detecção e diagnóstico precoces desta doença, sendo mais um fator que auxilia o controle dessa ameaça emergente para a saúde global $^{2}$, não esquecendo da importância da associação com os testes laboratoriais específicos, (RT-PCR, definido como o padrão-ouro, e outros exames sorológicos como os testes de dosagem de imunoglobulinas, de maneira a verificar o nível de ativação do sistema imunológico). 


\section{PADRÃO EM VIDRO FOSCO}

O padrão em vidro fosco na TC corresponde ao aumento da densidade (coeficiente de atenuação) dos pulmões, sem, no entanto, apagar o contorno vascular e as estruturas brônquicas, podendo evoluir para consolidação pulmonar (opacidade que apaga o contorno dos vasos). ${ }^{4}$ Lesões em vidro fosco tem aspecto heterogêneo ocupando parcialmente o espaço aéreo (alvéolos) comprometendo também pequenos vasos, brônquios. Além disso, as opacidades em vidro fosco nos pacientes acometidos pelo COVID-19 geralmente apresentam acometimento bilateral e multifocal, distribuição periférica e predomínio nos campos pulmonares médios, inferiores e posteriores. $^{3}$

\section{CONSOLIDAÇÃO PULMONAR}

Além de encontrar as opacidades pulmonares em vidro fosco na maioria dos casos de COVID-19, são observados, ocasionalmente, consolidações, com distribuição predominantemente periférica, por vezes associadas a reticulado fino (configurando o padrão de pavimentação em mosaico, definido como uma superposição das opacidades em vidro fosco), espessamento vascular e o sinal do halo invertido. ${ }^{1}$ Este sinal, definido como uma área com atenuação em vidro fosco circundada, parcial ou completamente, por um anel de consolidação, é um achado radiológico observado na pneumonia pelo novo coronavírus, já sendo relatado em outras pneumonias virais. Quando identificado, ocorre naquelas apresentações com sintomas mais tardios, sugerindo a correlação fisiopatológica subjacente do processo da doença conforme ela se organiza. ${ }^{5}$ A consolidação, ao contrário do padrão em vidro fosco, obscurece os vasos locais e as margens dos brônquios por ser caracterizada pela substituição do ar do espaço alveolar por células ou fluidos patológicos. Tendem a ser mais tardias, frequentes após o surgimento de opacidades reticulares e do padrão de pavimentação em mosaico.

\section{ANÁLISE DOS ACHADOS NAS RADIOGRAFIAS DE TÓRAX}

Radiografia de tórax em pacientes com suspeita de COVID-19 não é recomendada rotineiramente na prática clínica, porque é insensível à detecção do COVID-19 no estágio inicial por mostrar opacidades pulmonares mal definidas. ${ }^{6}$ À medida que a doença progride além do estágio inicial, a radiografia do tórax pode detectar várias opacidades irregulares nos pulmões (Figura 2A). Essas opacidades acabam se tornando confluentes e casos graves podem aparecer como opacidades densas ou consolidações. Em casos mais avançados, as radiografias de tórax, além da opacidade, podem demonstrar fluido pleural. Opacidades progressivas e consolidações foram observadas nas radiografias de tórax ao longo da evolução da doença. ${ }^{2}$

\section{ANÁLISE DOS ACHADOS NA TC DO TÓRAX}

A TC do tórax é altamente recomendada, por ser bastante sensível à detecção de sinais precoces, permitir avaliar a natureza e extensão das lesões, bem como detectar alterações sutis que geralmente não podem ser detectadas nas radiografias de tórax. Estes achados sutis auxiliam muito quando existe suspeita clínica de pneumonia grave e doenças respiratórias potencialmente fatais, como a síndrome do desconforto respiratória agudo grave (SDRA) associada ao COVID-19. ${ }^{2}$ O reconhecimento desses achados na TC (Figura 2.B e 2.C) permite agilizar a indicação de tratamento mais agressivo em pacientes com possível COVID-19 e são importantes também quando encontrados em pacientes examinados por outras causas que não a infecção por coronavírus, nos quais uma avaliação clínica mais cuidadosa se impõe.

Figura 2. Radiografia de tórax e tomografia computadorizada de pacientes com achados clínicos característicos

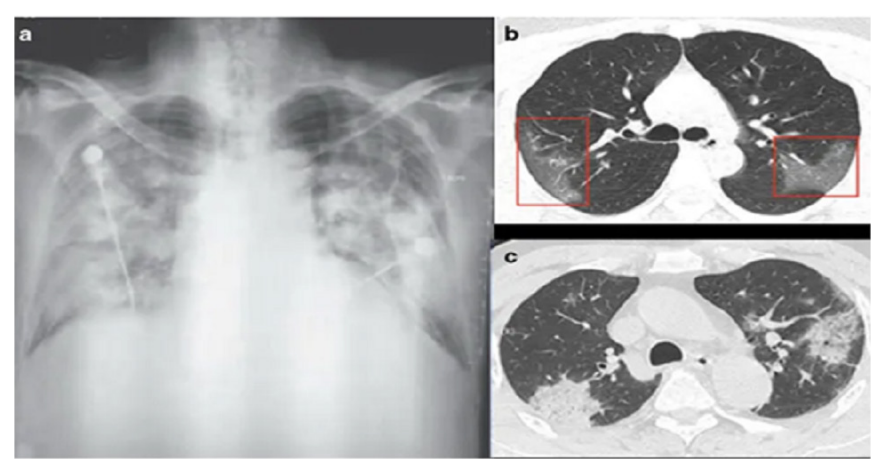

(A) Radiografia de tórax em um homem de 61 anos demostrando opacidades irregulares bilaterais, um pouco nodulares, nos campos pulmonares médio e inferior. (B) Imagem de tomografia computadorizada (TC) em uma mulher de 33 anos de idade, demonstrando opacidades em vidro fosco na periferia de ambos os pulmões. Os padrões bilaterais e periféricos de opacidades são achados comuns e característicos da nova pneumonia por coronavírus em 2019. (C) tomografia computadorizada do tórax de um homem de 71 anos mostra consolidação periférica no lobo superior direito e área irregular de opacidade em vidro fosco com algum espessamento septal intra e interlobular associado no lobo superior esquerdo. ${ }^{2}$

\section{DIAGNÓSTICO A PARTIR DOS SINTOMAS ATÍPICOS}

Diagnóstico possível de COVID-19 deve ser considerado em pacientes sintomáticos, que nos últimos 14 dias tenham apresentado contato próximo com um caso suspeito ou confirmado de COVID-19, que tenham estado em áreas onde a transmissão disseminada tenha sido documentada, ou ainda que tenham tido potencial exposição por participação em eventos ou por terem estado em locais em que casos de COVID-19 foram descritos, além de poderem apresentar manifestações clínicas mais comumente descritas, como febre, fadiga, tosse seca, anorexia, mialgia, dispneia e produção de catarro. A TC do tórax, nesse caso, pode ajudar no diagnóstico dessa doença, porém, isoladamente, não pode confirmá-lo nem excluí-lo. Quando utilizada a RT-PCR como referência, a TC do tórax apresenta alta sensibilidade (97\%), porém, baixa especificidade (25\%), dada a sobreposição dos achados com infecções pulmonares de diferentes etiologias. ${ }^{1}$

Vale ressaltar que pouco foi publicado sobre a apresentação de pacientes com COVID-19 com sintomas além de febre e problemas respiratórios, e muitos pacientes não são testados 
laboratorialmente se não apresentarem esses dois sintomas típicos. No entanto, nem todos os pacientes apresentam os sintomas esperados, alguns apresentaram sintomas gastrointestinais antes de apresentarem algum sintoma respiratório, por isso, o radiologista abdominal deve relatar e interrogar a possibilidade diagnóstica de COVID-19 quando, ao avaliar as bases pulmonares, encontrar achados sugestivos. ${ }^{7}$

Os achados nas bases pulmonares foram descritos pelos radiologistas abdominais como opacidades periféricas e subpleurais em vidro fosco, geralmente bilaterais, com configuração nodular, aparência aparentemente inespecífica, mas típica do COVID-19, como demostrada na Figura 3. $\mathrm{O}$ diagnóstico diferencial foi sugerido pelo radiologista abdominal primeiro e não era originalmente suspeito no pronto-socorro devido à falta de sintomas pulmonares típicos esperados. Os testes subsequentes de PCR para SARS-CoV-2 confirmaram essas suspeitas. ${ }^{7}$

Figura 3. Tomografia computadorizada mostrando achados nas bases pulmonares típicos do COVID-19 em um paciente que relatava dor abdominal.

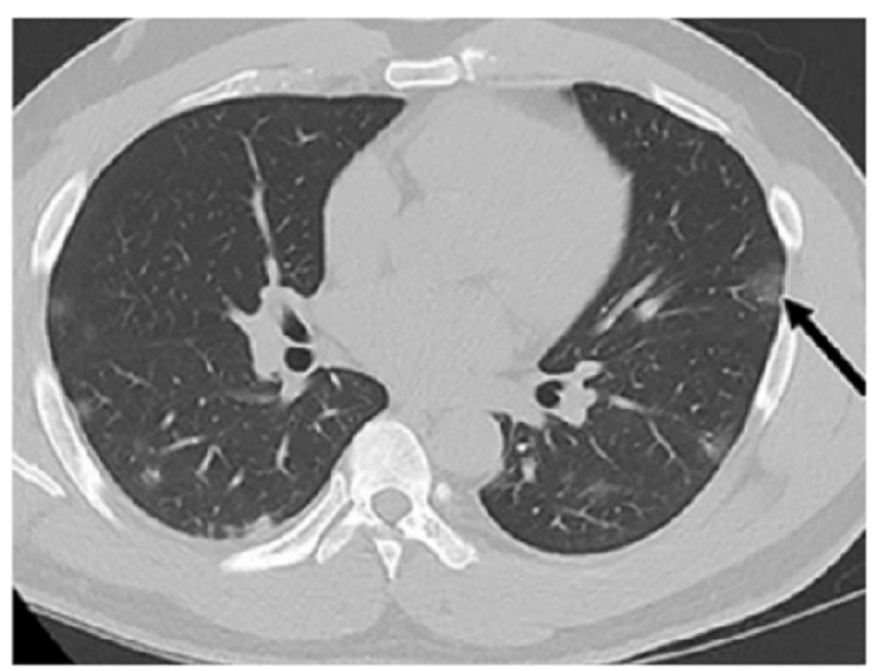

Na figura acima, homem de 40 anos com dor abdominal e sintomas gastrointestinais. A TC axial do abdome e da pelve mostra opacidades subpleurais multifocais em vidro fosco (seta) nos pulmões visualizados. Esse achado inespecífico pode ser resultado de infecção atípica, como pneumonia por doença de coronavírus (COVID-19) ${ }^{7}$.

\section{DIAGNÓSTICO DIFERENCIAL}

O diagnóstico diferencial entre COVID-19 e outras infecções pulmonares ou doenças não infecciosas é muito importante, mas também muito difícil devido às suas características de imagem. A história epidemiológica, os sintomas clínicos, as manifestações laboratoriais e de imagem devem ser consideradas de forma abrangente antes do diagnóstico. Mas o diagnóstico confirmado deve se basear na etiologia eventualmente. Embora o diagnóstico definitivo não possa ser feito apenas com base nos recursos de imagem, os padrões de imagem podem ajudar a melhorar a precisão do diagnóstico nesta doença, desde que os pacientes apresentem piora dos sintomas e/ou desenvolvimento de complicações. Desse modo, é fundamental diferenciar de outras doenças, como as pneumonias virais, pneumonias bacterianas, pneumonias micoplasmáticas e doenças não infecciosas. ${ }^{8}$

Ademais, estudos demonstraram que o COVID-19 pode apresentar um padrão de tomografia computadorizada do tórax semelhante à pneumonia em organização, notadamente as opacidades periféricas em vidro fosco (GGO), geralmente bilaterais e multilobares. Em relação ao método de coleta, cultura de escarro e swab orofaríngeo são menos sensíveis. Como as pneumonias virais normalmente não resultam na produção de escarro purulento, o swab nasofaríngeo é o método preferido para a coleta de amostras. ${ }^{9}$

Deve-se notar que as pneumonias virais têm uma ampla variedade de manifestações de imagem, algumas das quais são atípicas ou pouco comuns no quadro de COVID-19, como opacidades em "árvore em brotamento" (tree in bud), pequenos nódulos, espessamento da parede brônquica e tampões de muco bronquial. ${ }^{9}$

Já as características típicas são aquelas relatadas na literatura como frequentes e mais especificamente vistas na pneumonia por COVID-19 na pandemia atual (Figura 4.A e 4.B). O principal diagnóstico diferencial inclui algumas pneumonias virais (Figura 4.C), especialmente influenza (Figura 4.D), e padrões agudos de lesão pulmonar, particularmente pneumonia em organização, seja secundária, como por toxicidade de drogas e doença do tecido conjuntivo ou idiopática. ${ }^{9}$

Figura 4. Tomografias computadorizadas demonstrando achados clínicos em pacientes com COVID-19 e pacientes com diagnósticos diferenciais como pneumonias.

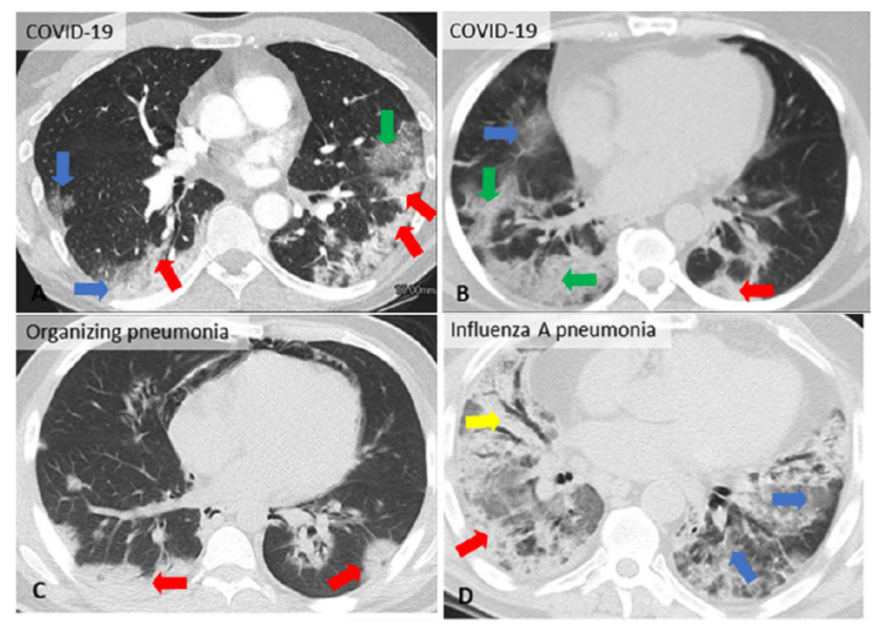

Legenda: vidro fosco (seta azul), consolidação (seta vermelha), vidro fosco com septos interlobulares espessados (seta verde), consolidação com broncogramas aéreos (seta amarela).

Achados de TC em casos de COVID-19 e outras doenças com alterações semelhantes (diagnóstico diferencial). Opacidade em vidro fosco posterior, periférica e arredondada 
e consolidação nas imagens axiais de quatro pacientes; COVID-19 (A, B), pneumonia em organização secundária a dermatomiosite (C) e pneumonia por influenza A (D). A pneumonia em organização e a pneumonia por influenza podem ser indistinguíveis do COVID-19 através de TC. Atualmente, a TC de rastreamento para diagnóstico ou exclusão do COVID-19 não é recomendada pela maioria das organizações profissionais ou pelos Centros dos EUA para Controle e Prevenção de Doenças. ${ }^{9}$

Torna-se claro, portanto, que em pacientes portadores de COVID-19, o assunto é complexo e que a pneumonia viral é uma hipótese razoável, que deve ser ou não descartada através da história clínica e exames complementares. Como sempre, os radiologistas devem seguir os parâmetros de prática para a comunicação dos achados de diagnóstico por imagem. ${ }^{9}$

\section{CONCLUSÃO}

A radiografia de tórax é a modalidade mais conveniente e econômica para a triagem e acompanhamento da maioria das doenças pulmonares. No entanto, para a manifestação de imagem inicial do COVID-19, opacidade do vidro fosco ( $G G O$ - ground glass opacity em língua inglesa), a radiografia de tórax apresenta baixa sensibilidade. A TC é recomendada para a triagem do COVID-19, porém, não deve ser usada isoladamente para diagnóstico, nem tampouco deve ser realizada para rastreamento da doença, já que alguns exames não apresentam alterações radiológicas nos estágios

\section{REFERÊNCIAS}

1. Chate RC, Fonseca EK, Passos RB, Silva Teles GB, Shoji H, Szarf G. Apresentação tomográfica da infecção pulmonar na COVID-19: experiência brasileira inicial. J Bras Pneumol. 2020;46(2):e20200120.

2. Yang W, Sirajuddin A, Zhang X, Liu G, Teng Z, Zhao S, et al. The role of imaging in 2019 novel coronavirus pneumonia (COVID-19). Eur Radiol. 2020;15:1-9.

3. Araujo-Filho JD, Sawamura MV, Costa AN, Cerri GG, Nomura CH. Pneumonia por COVID-19: qual o papel da imagem no diagnóstico? J Bras Pneumol. 2020;46(2):e20200114.

4. Raptis CA, Hammer MM, Short RG, Shah A, Bhalla S, Bierhals AJ, et al. Chest CT and coronavirus disease (COVID-19): a critical review of the literature to date. AJR Am J Roentgenol. 2020;26:1-4.

5. arias LD, Strabelli DG, Sawamura MV. Pneumonia por COVID-19 e o sinal do halo invertido. J Bras Pneumol. 2020;46(2):e20200131.

6. Moreira BL, Brotto MP, Marchiori E. Chest radiography and computed tomography findings from a Brazilian patient with COVID-19 pneumonia. Rev Soc Bras Med Trop. 2020;53(2):e20200120.

7. Siegel A, Chang PJ, Jarou ZJ, Paushter DM, Harmath CB, Arevalo JB, Dachman A. Lung base findings of coronavirus mais precoces da doença, ${ }^{10}$ enquanto a radiografia de tórax desempenha um papel importante no acompanhamento dos casos graves e críticos. A TC de alta resolução é a melhor opção para detectar opacidades pulmonares em paciente suspeito de COVID-19, e evita o achado falso-negativo de vidro fosco, que pode ocorrer quando esta técnica não é utilizada.

Nas linhas de frente do combate à epidemia de COVID-19, a imagem do tórax (principalmente a TC quando indicada), até o presentemomentotem tidoumpapel complementarnodiagnóstico precoce do COVID-19, porém, os achados tomográficos não são preditores da evolução clínica nem unicamente responsáveis pelo diagnóstico dessa doença, enquanto que os exames de imagem juntamente ao RT-PCR podem auxiliar na detecção do SARS-CoV-2, o que permite diagnóstico e tratamento precoces, prevenindo o retardo do isolamento do paciente.

Desse modo, por serem exames complementares, recomenda-se que o diagnóstico final da doença seja pautado nas informações clínico-epidemiológicas associadas aos exames RT-PCR e/ou sorologia. ${ }^{11}$ Clínicos e radiologistas devem estar familiarizados com o espectro de acometimento do COVID-19, assim como com a evolução esperada dos achados, como forma de contribuir para identificar e tratar precocemente os pacientes acometidos e, consequentemente, auxiliar na redução das consequências e da taxa de mortalidade da doença. Além disso, a TC do tórax deve ser reservada para a avaliação de complicações da pneumonia por COVID-19 ou quando houver suspeita de diagnóstico alternativo.

disease (COVID-19) on abdominal CT in patients with predominant gastrointestinal symptoms. American J Roentgenol. 2020;17:1-3.

8. Fan L, Li D, Xue H, Zhang L, Liu Z, Zhang B, et al. Progress and prospect on imaging diagnosis of COVID-19. Chin J Acad Radiol. 2020;18:1-0.

9. Simpson S, Kay FU, Abbara S, Bhalla S, Chung JH, Chung M, et al. Radiological Society of North America Expert Consensus Statement on Reporting Chest CT Findings Related to COVID-19. Endorsed by the Society of Thoracic Radiology, the American College of Radiology, and RSNA. Radiol Cardiothorac Imaging. 2020;25;2(2):e200152.

10. Farias LD, Strabelli DG, Fonseca EK, Loureiro BM, Nomura $\mathrm{CH}$, Sawamura MV. Alterações tomográficas torácicas em pacientes sintomáticos respiratórios com a COVID-19. Radiol Bras. 2020;53(4):255-61.

11. Colégio Brasileiro de Radiologia e Diagnóstico por Imagem. Recomendações de uso de métodos de imagem para pacientes suspeitos de infecção pelo COVID-19. São Paulo: CBR; 2020 [acesso em: 9 jun 2020]. Disponível em: https://cbr.org.br/wpcontent/uploads/2020/03/CBR_Recomenda\%C3\%A7\%C3\%B5esde-uso-de-m\%C3\%A9todos-de-imagem.pdf

\section{Como citar:}

Silva LS, Andrade KC, Soares ML. Exames de imagem como método complementar para o diagnóstico da COVID-19: revisão integrativa de literatura. Rev Med UFC. 2021;61(1):1-8. 